\title{
Investigating the Impact of Organizational Commitment on the Financial Performance in Indian Banking Sector
}

\author{
${ }^{1}$ Nader Naghshbandi, ${ }^{2}$ Vineet Chouhan, ${ }^{3}$ Fatemeh Yousefpoor,,${ }^{4}$ Shaban Mohammadi \\ 1, Department of Accounting- Hakim Nezami institution of higher education at Quchan-Iran \\ 2, Assistant Professor, School of Management, Sir Padampat Singhania University, \\ Bhatewer, Udaipur. Tel: +91-97-7277-8431, E-mail: vineet.chouhan@spsu.ac.in \\ 3, Master of Accounting at Islamic Azad University-Shirvan Branch-IRAN \\ 4, Department of Accounting- Hakim Nezami institution of higher education at Quchan-Iran.
}

Received: September 11, 2017., Revised: December 29, 2017., Accepted: December 29, 2017.

\begin{abstract}
Organizational commitment (OC) is one of the most important attitudes and/or organizational variables. It is one of the important factors for increasing organizational performance and consequently it has a significant impact on productivity enhancement. Study of behavior in the workplace due to the great importance of manpower compared to other resources within the organization is of great importance too. OC is a psychological state which represents kind of desire, a need and a requirement for continuing employment in an organization. It is considered as one of the most influential factors in getting success and competitive advantage in today's organizations. Investigating effect of financial and non-financial variables on financial performance for a long-term has engaged the minds of researchers. Intensification of competition in markets has increased importance of recognizing competitive advantage patterns and their effect on financial performance (FP).This research conducted to provide a better understanding for people as well as for aggregation of a research subject OC and FP is compared in Indian banking sector by taking sample of 2 public and two private banks the correlation between the OC and FP and the results included a positive and significant correlation. Desired FP to increase wealth is an essential and obvious issue. According to the issued subjects, today, commitments and their impact on FP of companies have become increasingly important. In Indian banks the correlation between the OC \& FP were found significant.
\end{abstract}

Keywords: organizational commitment; financial performance; market value, organizational performance.

\section{Introduction}

The current era is a time of rapid and unpredictable developments. Current status of society indicates an imbalance in the increasing complexity of organizations and their inability in predicting and confronting these developments and complexities. Organizations to deal with environmental threats and the use of opportunities, they themselves must be the source of the wave and evolution and to adapt themselves to these changes to respond to the new needs of modern civilization (Norouzi Seyed Hosseini and Kalateh Seyfari, 2014). Study of behavior in the workplace because of the great importance of manpower compared to other resources within the organization is of great importance (Farhangi, 2009). One of the most important attitudes or organizational variables is organizational commitment. Organizational commitment is one of the factors that increases organizational performance and consequently it has a significant impact on productivity enhancement. Overall Attitude of Organizational Commitment is an important factor for understanding organizational behavior and it is a good predictor of desire to remain in the job. This attitude over the past three decades has changed, and perhaps the most significant change in this domain is about the concept in a multi-dimensional manner. On the other hand, the lack of feeling organizational commitment creates a big problem, which affects the performance of human resources. Managers have well understood that the most important factor in gaining competitive advantage is the organization's human 
resources. Therefore, attention to the issue of commitment and loyalty of human resources to the organization and performing as best as possible the roles assigned to them and even beyond-organization duties by human resources are the serious concerns of managers of organizations (Shefat et al., 2013).

Organizational commitment is a linkage of people to organization that is characterized by three factors: a) strong belief and acceptance of the goals of the organization's values; b) great desire to organization; c) strong desire to stay in organization (Hoveida et al., 2012).

\section{Theoretical foundations background research}

Corporate performance is considered to be important to managers. At the present time, achieving economic growth through upgrading and improving the performance is one of the most important economic goals of countries. Progress of many organizations has been due to improved performance (Akbari Darian, 2010). Focus of organizational commitment is when a person can be committed to the organization, administration, a special person or other employees and employer. Movement of employees toward organizational commitment can be a challenge for managers (Farhangi, 2009). Today organizations are so widespread and sophisticated that their management and decision making about affairs of an organization is beyond the control of only an individual. This is an indication that human being has always been involved with rational constraints. On the other hand, according to the results of researches related to the management science, we conclude that the core capital of organization is in its human resources and the effective and optimal use of these potential and human resources ensures the success and effectiveness of the organization (Salajegheh and Honaramooz, 2010).Organizational commitment is a psychological state that indicates kind of willingness, need and obligation to continue employment in an organization (Alan and Mayer, 1990). Willingness means individual's desire to continue his service in the organization. The need means that individual due to the investments he has made in the organization has no option except that to continue his service in the organization. Obligation means that religion, responsibility and duty that individual has against the organization and sees himself obliged to stay in organization. According to Robbins, organizational commitment is a state that in which individual describes an organization as part of his identity and wishes to keep his membership in the organization (Robbins, 2005; quoted by Shafaghat et al., 2013).Organizational commitment actually indicates loyalty and commitment of employees to their organization. When employees are loyal to the organization, costs they must pay to train new staff decreases. Recruiting and replacing any new force costs to the organization about 70 to 200 percent of income of the previous employee who has left the organization (Kaye \& Jordan-Evans, 2001, quoted by Ramezanian et al., 2013).Organizational commitment is kind of emotional attachment to the organization so that staffs who are very committed and take their identity from the organization, participate in the organization and enjoy being a member in the organization (Hosseini and Mehdizadeh Ashrafi, 2009). Employees' commitment to the organization is a producer of intangible assets (Abu al-Alaie, 2004). There is no single definition for organizational commitment, but from all the definitions it turns out that organizational commitment includes general personality characteristics of individual. In fact, organizational commitment is part of the personality organization of an individual and it seems that is related to other influential factors in his life (Hajloo et al., 2013: 59). In this study, organizational commitment components, which are three types, are examined.

Emotional commitment: emotional or attitudinal commitment occurs when employees because of their emotional continuity have a desire to stay in the organization. Through emotional commitment, employees become aligned with the organization and internalize the values and attitudes of the organization and their demands in the organization realizes. Emotional commitment is largely correlated with perceived organizational support (Shore \& Tetrick, 1991).

Continuous commitment: it is expected costs caused by abandonment of organization and indicates that employees need it because they cannot do anything else. The more the person's investment in the organization is, the less would be probability of quitting job by him and so his organizational commitment would increase (Hoveida et al., 2012).

Normative commitment: it comes from values of employees. People has the belief that they owe their organization and so they remain there and they see this as best thing they can do (Mahdad, 2010).According to Iranian accounting standards, business unit financial performance includes returns earned from sources controlled business unit. Information about financial performance are included in profit and loss statements as well as in comprehensive profit and loss statements (Mahmoudi, 2010).In our country, there has been a lot of research on organizational commitment, but little research on the relationship between organizational commitment and performance of organization, especially the financial performance of organization, there exists. So considering this 
issue, the researcher in this research aims to examine the relationship between organizational commitment and financial performance in Birjand Kavir Tire Factory.

The paper deals with the following research problems:

Is there a significant relationship between organizational commitment and financial performance?

What factors increase organizational commitment in the organization?

Organizational commitment is considered as one of the most influential factors in getting success and competitive advantage in today's organization (Ramezanian et al., 2013). Organizational commitment is one of the key components of successful organizations. Organizational commitment is the strong desire of employees to remain in an organization. In organizational commitment, individual considers the organization as part of his identity and he wishes to be a member of the organization. One of the main issues of organization is its ability to attract and retain more committed employees and this has a significant advantage (Jafarzadeh, 2005).In recent years, organizational commitment has been an important part of organizational studies and has been placed at its center, because its relationship with the quality of organizational life has been proven so that researches have shown that employees' commitment is a strong and effective force for the success of organizations (Calverson, 2002).Organizational commitment defines amount of employee engagement power with an organization and it is one of the main reasons for not leaving organization by employees and the more employees are committed to the organization; the more would be their satisfaction, motivation and performance (Neininer et al., 2010; quoted by Ramezanian et al., 2013).

In general, it can be said that efficient manpower is the major indicator of superiority of an organization to other organizations (Ismaili, 2001). Presence of committed human resource enhances reputation of organization in the community and provides the basis for the growth and development of other organization (Allahdadi, 2003).Investigating effect of financial and non-financial variables on financial performance from the far past has engaged the minds of researchers to itself. Intensification of competition in markets has increased importance of recognizing competitive advantage patterns as well as their effect on financial performance. Effective factors on corporate financial performance so far have been considered from different perspectives. One of the most commonly used of them is the Market Based-View (MBV) approach. This approach, despite having strengths has also been criticized in justifying differences in performance of companies (Barney, 1991).In response to these criticisms in the 1990s, resource-based view and more recently and more specifically the organization's capabilities are proposed and it has taken a lot of attention to itself. Among business leaders, there is a widespread agreement that organization's capabilities are essential for its continued growth and profitability (Wind, 2005). Resource-based view emphasizes on the existence of a relationship between the internal characteristics of an organization and organization's resources with its performance (Barney, 1991; Connor and Prahalad, 1996; Eisenhardt and Schoonve, 1996; Peterhof, 1993; Narasimhan et al., 2006).As it can be seen from researches done in this field, in recent years, attention to the company's capabilities and especially the impact of these capabilities on financial performance has increased, because better financial performance will create more wealth for shareholders. According to studies conducted in this area, most of them use the data-output framework for their models and less studies have been conducted so far that looks at this with a different and new look.Continuous improvement of organizations' performance creates a massive force of synergy that these forces can support the growth and development programs and create opportunities for organizational excellence. Governments, organizations and institutions employ promising attempts in this regard. Without reviewing and achieving awareness of progress and getting goals and without identification of challenges faced by organization and acquisition of feedback and being informed about the extent to which policies are implemented as well as identification of those cases that require serious improvement, continuous improvement of performance will not realize. All of the above mentioned cases without measurement and evaluation are not possible. English physicist, Lord Kelvin, about the necessity of measuring says: "whenever we were able to measure what we talk about and state it in terms of numbers and figures, then we can claim that we know something about the subject under discussion. Otherwise, our knowledge is incomplete and will never reach maturity (Rahimi, 2006: 36).Also, scholars and researchers believe that performance evaluation is a major issue in all organizational analyses and imagination of an organization without evaluating and measuring performance is difficult. Performance evaluation and measurement increases intelligence of system and invoke people to operate in the desirable direction and it is the main part of formulation and implementation of organizational policies.The company's financial performance includes variables such as profit, profit growth, sales and dividend, cash flows, earnings per share, financial ratios (including $\mathrm{P} / \mathrm{E}, \mathrm{ROE}$ and $\mathrm{ROA}$ ), ratio of market value to the stock value of the shares, and the ratio of Tobin's Q (Jahankhani and Parsayian, 2003).Today, industries and products are one of important, great and effective levers for economic development in any society and manpower in considered as a basic component in organizations. Given importance of organizational commitment and identifying factors affecting to that in general, 
especially its impact on improving financial performance and its components, the necessity of reviewing this issue among workers and employees of the factory is being felt. Therefore, present study aims to predict financial performance of the factory through organizational commitment and its components.

\section{Research method}

\subsection{Research conducted inside the country (IRAN)}

Shafaghat et al. (2013) examined impact of organizational commitment on the Performance of Industrial Companies based on the model of Meyer et al. (case study: Industrial Towns of Mazandaran Province). The results of this research showed that, among the dimensions of organizational commitment, emotional and normative commitment affects the financial and non-financial performance of industrial companies, and continuance commitment does not have any effect on performance. In the model, the value of fit indices (AGFI 0.90 \& GFI 0.97 ) indicate the suitability of the model.Poorsoltani et al. (2012). In this research, the relationship between organizational excellence and organizational commitment in Physical Education Institutions of Iran's Selected Provinces, the results of this study showed that there is a positive and significant relationship between organizational excellence and organizational commitment ( $\mathrm{p} 0.001$ and R 0.546 ). There was a positive and significant relationship between organizational excellence and each subscale of organizational commitment (emotional, continuance, and normative) $(\mathrm{p}<0.01)$. The emotional commitment has strongest ( $\mathrm{p} 0.0001$ and $\mathrm{r} 0.51$ ) and the continuance commitment has weakest ( $\mathrm{p} 0.001$ and $\mathrm{r}$ 0.309) relationship with organizational excellence. Also, there was a strong and significant relationship between enablers and results in organizational excellence model ( $\mathrm{p} 0.001$ and $\mathrm{r} 0.864$ ). According to the results of the present study based on the existence of a positive relationship between excellence and organizational commitment, it can be said that managers who intend to implement and perform the EFQM organizational excellence model, also it would be better to consider the organizational commitment of employees. Haghighat Monfared et al. (2010) in their article entitled the impact of organizational commitment on employees' performance stated that since attitude can act as an effective factor in shaping behavior, in the literature collection of the science of organizational behavior, many researches in the context of the relationship between these two topics have been performed. One of the issues that has attracted the attention of experts in this field was the organizational commitment. Organizational commitment has undergone a change over time, so that initial perspectives on this issue refer to the one-dimensionality of this concept and the more recent viewpoints refer to its multidimensional nature. One of the multidimensional patterns of organizational commitment is the three-dimensional pattern of two major thinkers in this field, Meyer and Allen, and they stated that an organizational commitment includes three components, i.e. emotional commitment, normative commitment, and continuance commitment. On the one hand, performance is a method of doing work, sometimes synonymous with the results and outcome of employee's work, has been one of the permanent challenges of the organization's management. This research is intended to investigate the relationship between organizational commitment and its dimensions with the performance of independent employees, as a case study, in the gas company of West Azarbayejan province. The results of the research indicate that there is a significant statistical relationship between each of the three dimensions of organizational commitment with employees' performance. In addition, the main hypothesis of the research, which examines and tests the relationship between performance and organizational commitment of employees in general, has been confirmed. According to the findings of this research, based on the strong relationship between the two variables of organizational commitment and employee performance, it is suggested that managers pay attention to strategies that improve the organizational commitment for improving the staff performance. Bagheri and Tavanaei (2010) in their research examined the organizational commitment and organizational performance. In this research, he concluded that organizational commitment of employees can result in a sense of satisfaction, affiliation, attachment and connection to the organization, more desirable job performance, decreased staff exit from the organization, active social behavior, non-absenteeism, altruism, helping colleagues and reducing occupational stress as well as financial success and increasing the effectiveness and productivity of the organization.

\subsection{Research conducted abroacd}

In an article entitled "The heterogeneous resource-based views of the relationship between company performance and company capabilities," Di Sarbou, Dibenedetto and Michael Sang (2007) sought a new model for organization's capacities and performance. In this study, they sought to use a heterogeneous approach with the approach (RBV) and the development of research lines with heterogeneous modeling of these relationships. They have tested these 
relationships in ddifferent industries. This study used the regression model to test relationships and found that managers should invest more in the organization's capabilities to maximize their financial performance and the company. This study helped considerably to understand the functional effects of investing in capabilities in the framework of RBV.Nath et al. (2008) in their study, aimed at understanding the relative effectiveness of the company's capabilities (marketing and operations) and diversification strategy on financial performance. They assumed that this relationship depends on the relative efficiency of the company in combining the three elements of source-capability -performance. The study was conducted on 102 British logistics companies and the results indicated that marketing capability was the main determinant of outstanding financial performance. The findings showed that market-oriented companies are likely to have better business performance than companies that focus only on their operational capability. Also, when companies focus on a limited portfolio of services / products and a large geographic market, they have better performance.Wright et al. (2003) examined organizational commitment and human resource processes among independent business units of a company, and concluded that both variables (commitment and human resource processes) were remarkably consistent with different performance criteria (quality and productivity) in addition to operating costs and gross unit profit.In his research, Bonkhoff (1997) examined organizational commitment and the performance of organizations in sales goals and the organizational profit margin. He concludes that organizational commitment is significantly related to organizational financial success.As researches have shown in this regard, in recent years, the human resources of the organization, and especially the relation of this organizational commitment to financial performance have been paid more attention because better financial performance will create more wealth for shareholders.Organizational commitment: Organizational commitment is one of the important occupational and organizational attitudes that has been and continues to be popular over the last few decades by many researchers in the fields of organizational behavior and psychology, especially social psychology. This attitude has undergone some changes during the past three decades, and it seems that the most significant changes in this domain relate to the "multidimensional attitude" in this sense rather than "one-dimensional attitude" (Farhangi and Hosseinzadeh, 2005).Financial performance of the organization: According to Iran's accounting standards, the entity's financial performance includes the return on the assets under the control of the business entity. Information about financial performance is provided in the form of a comprehensive statement (Mahmoodi, 2010).

\subsection{Current study}

To investigate the impact of organizational commitment on financial performance in selected public and private banks in India, financial data and survey results have been used as input to the model.To portray the distilled results, the organizational commitment index has been calculated embodying the three major building blocks of organizational commitment of banking institutions in India. To highlight the compelling evidences linking organizational to financial metrics, financial ratios benchmarked on CAMEL model have been used. Financial ratios are calculated on different scales, so it is imperative to develop a concrete model to investigate the overall financial performance of commercial banks. For this purpose, discriminate analysis has been done and the selected commercial banks have been classified in 'high profitability group' and 'low profitability group' on the basis of discriminate score.To explore the link between organizational commitment and financial performance two powerful statistical tools viz. Correlation analysis and Circumflex modeling have been used. Correlation analysis is used to calculate the degree of association among the different organizational variables and the financial performance measures. Circumflex modeling has been used to comparatively portray the integrated graphical presentation of facts and figures explaining the impact of organizational on financial performance.

\section{Analysis}

\subsection{Circumflex Report}

A culture profile of the selected banking institution is presented with the help of Circumflex model. Circumflex Model is an integrated graphical representation of the data came from organizational commitment survey of selected banking institutions in India. Based on several acknowledged psychological and management theories, this model was created by the American professor Robert A. Cook and the psychology specialist, J. Clayton Lafferty (1971), known as the Circumflex model. It is an instrument used to measure attitudes and behaviors, styles adopted in the organization. 


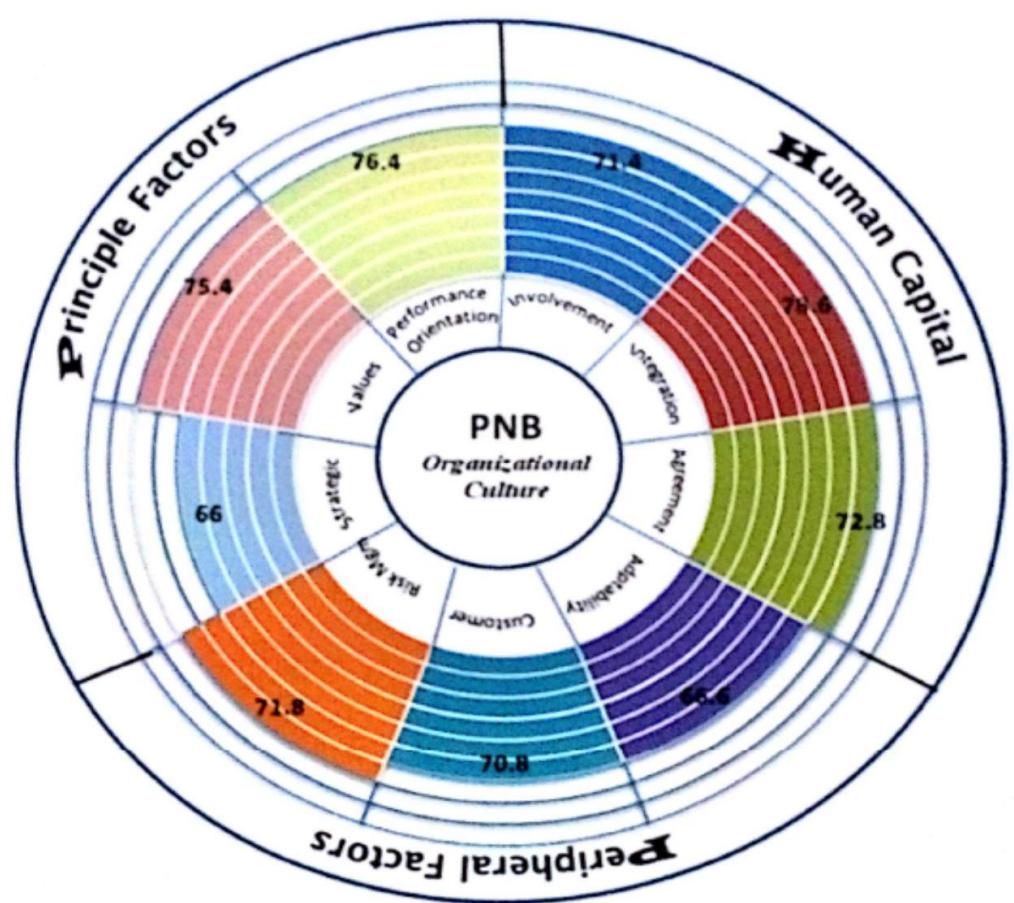

$<$ Figure 1> Panjab national bank-India: Organizational Commitment score72.2 \& Financial performance score 0.496

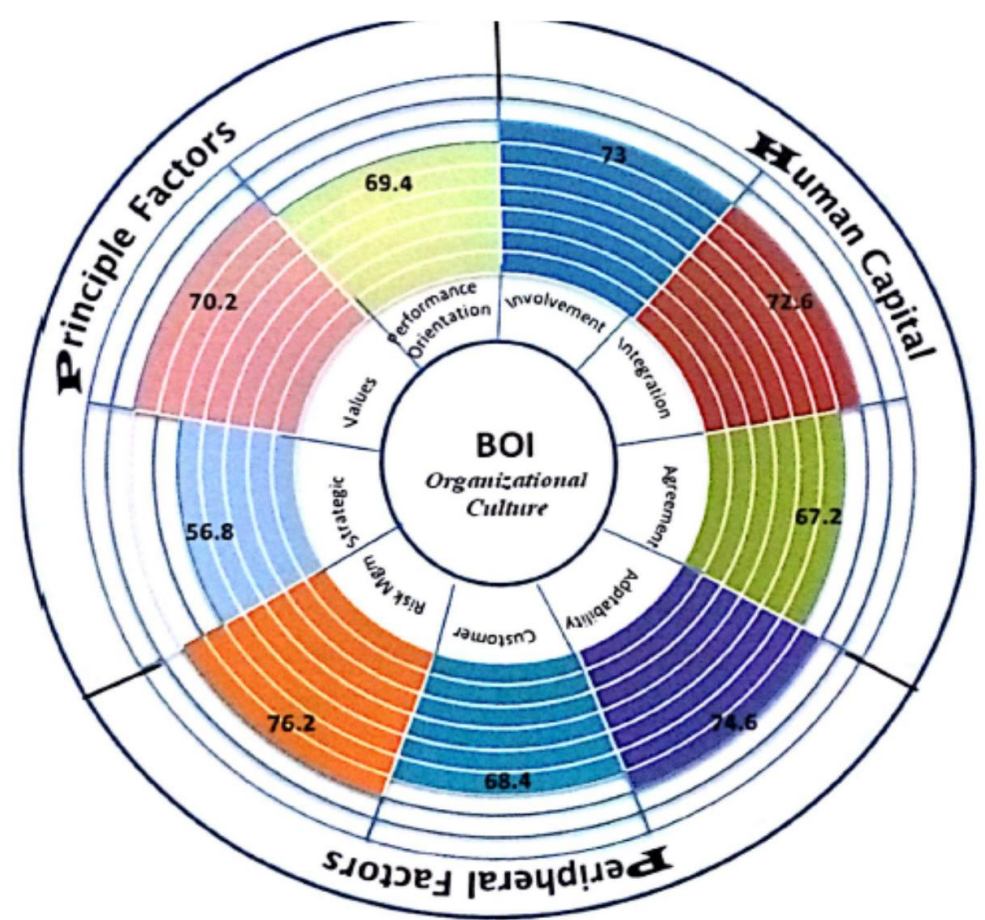

$<$ Figure 2> Bank of India-India: Organizational Commitment score 69.8 \& Financial performance score -1.279 


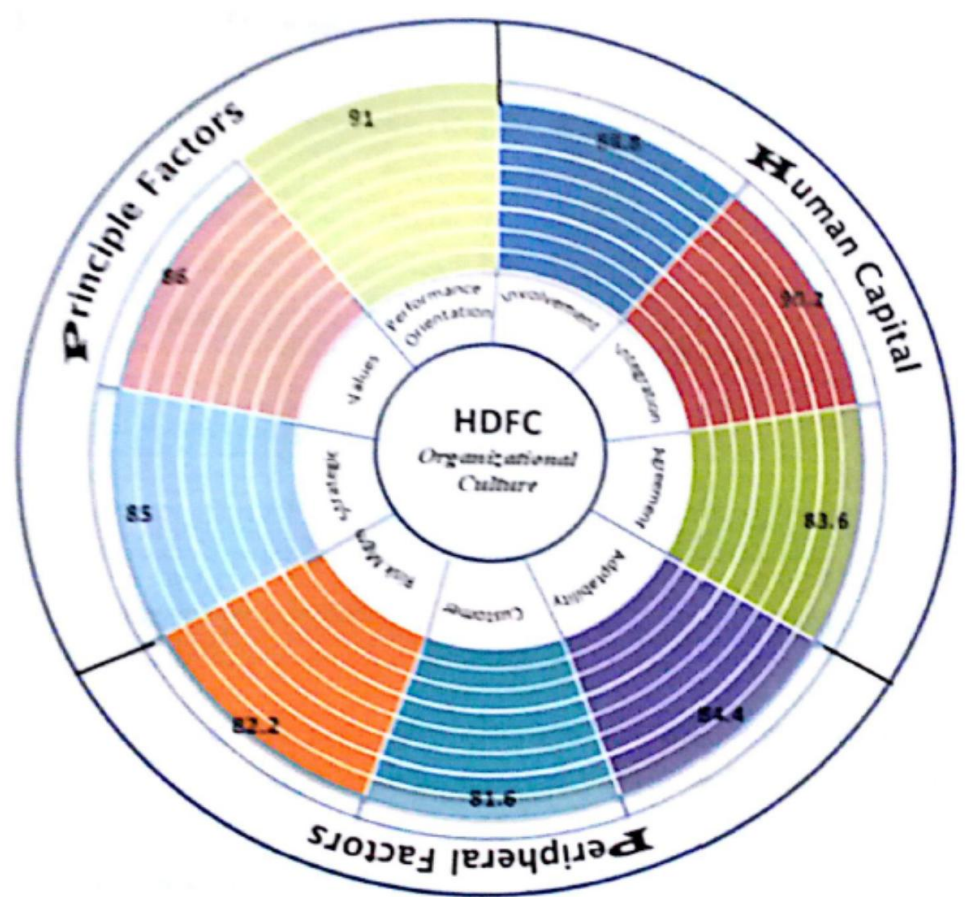

$<$ Figure 3> HDFC Bank -India: Organizational Commitment score 85.6 \& Financial performance score 2.707

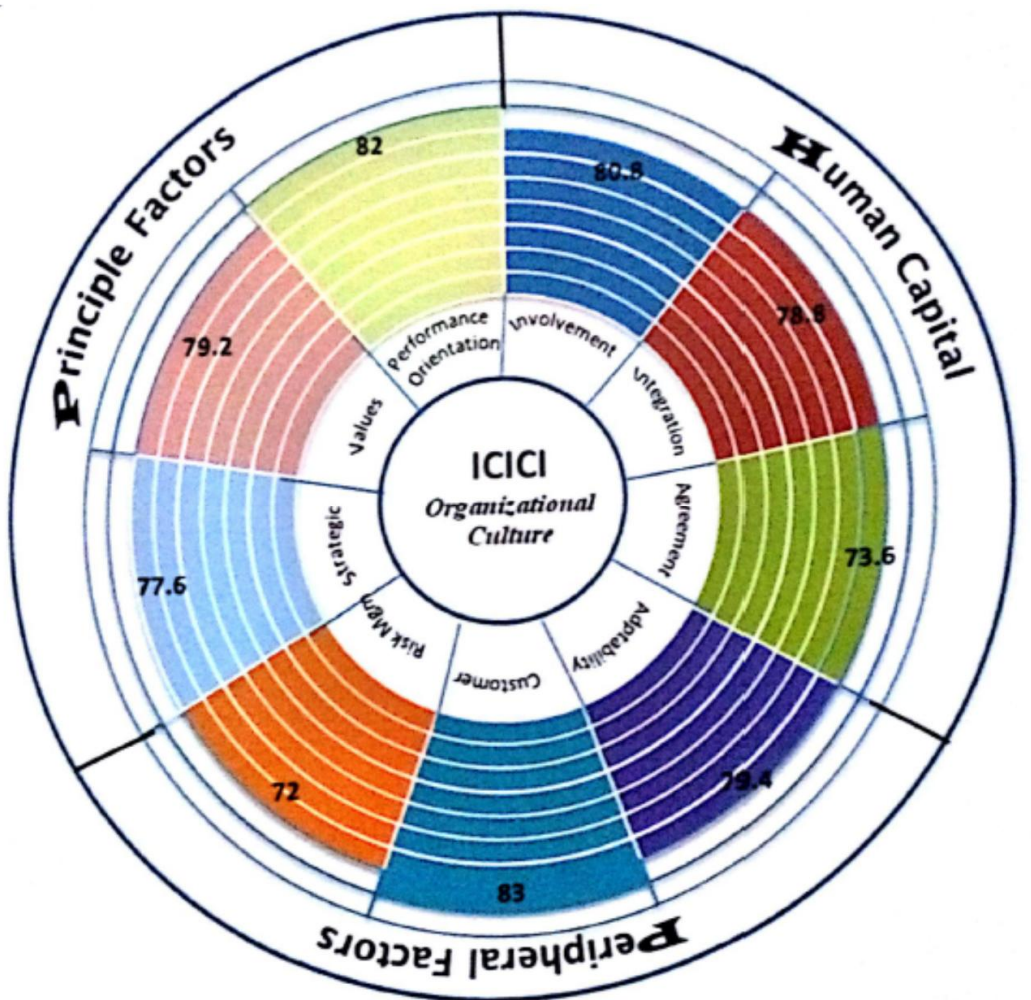

$<$ Figure 4> ICICI Bank-India: Organizational Commitment score 79.0 \& Financial performance score 1.429 
$<$ Table 1 > Comparative score of Organizational Commitment \& financial performance

\begin{tabular}{|c|c|c|c|c|}
\hline \multirow{2}{*}{ Bank } & \multicolumn{2}{|c|}{ Organizational Commitment } & \multicolumn{2}{c|}{ Financial performance } \\
\cline { 2 - 5 } & Score & Relative performance & Financial discriminant group & Profitability group \\
\hline PNB & 72.2 & 3 & 0.496 & High \\
\hline BOI & 69.8 & 4 & -1.297 & Low \\
\hline HDFC & 85.6 & 1 & 2.707 & High \\
\hline ICICI & 79 & 2 & 1.429 & High \\
\hline
\end{tabular}

The above table exhibits the comparative status of selected public and private sector banks in relation their financial performance and organizational culture score. The figures reveal the fact the banking institutions strong culture is enjoying relatively biller financial position. The above table exhibits the comparative status of selected public and private sector banks in relation their financial performance and organizational culture score. The figures reveal the facts the banking institutions strong culture are enjoying relatively biller financial position. The examinations of above facts and figures shed light on the link between organizational commitment financial performances. In the present case, HDFC bank stated at the first position carrying highest organizational culture score viz.85.6 and as resultant the bank falls under the high profitability group with 2.707 discriminant score at the lowest extreme point. Bank of India stands at last position in terms of organizational culture score and falls the low profitability group with a negative discriminant score (-1279). These figures present the impact of organizational commitment financial metrics as stronger organizational culture status reads biller financial position

\subsection{Correlation between the organizational commitment and financial performance}

The correlation between the organizational commitment and financial performance is enlisted as under:

$<$ Table 2> Pearson Correlations

\begin{tabular}{|c|c|c|c|}
\hline \multicolumn{2}{|c|}{} & Organizational commitment & Financial performance \\
\hline \multirow{2}{*}{ Pearson Correlation } & Organizational commitment & 1.000 & .588 \\
\cline { 2 - 4 } & Financial performance & .588 & 1.000 \\
\hline \multirow{2}{*}{ Sig. (1-tailed) } & Organizational commitment &. & .000 \\
\cline { 2 - 4 } & Financial performance & .000 &. \\
\hline
\end{tabular}

Table-2 results as significant positive correlation $(0.5888 \& \mathrm{p} 0.000)$ between the two, It revealed that organizational commitment affects financial performance in the selected banking companies in India.

\section{Conclusion and suggestions}

\subsection{Conclusion}

In the problem statement, one of the challenges faced by organizations is to find out what are the associated factors of organizational commitment that affects financial performance, in order to improve it. The desirable financial performance to increase wealth is obvious and necessary. According to the discussed issues, today, their commitments and impacts on financial performance of companies have become increasingly important.

In our country, we can say that some of the strategic mechanisms are related to the indicators of financial performance of companies. The most important factors in increasing the organizational commitment of employees, according to the articles in the main part of the article on organizational commitment, are as follows:

- Emphasis on teamwork and group working in dealing with issues and solving them.

- Creating a constructive and effective relationship between the staff and central managers and increasing bilateral interaction of staff with the management and criticism of managers and supervisors.

- On time encouragement and increasing salaries, especially increased revenues

- Equitable treatment with respect for managers and supervisors in the work environment

- Awareness of employees about the organization's goals, changes and reasons 
- Emphasis on the role of management, especially mid-level managers and direct supervisors in coordinating staff with organizational culture.

- A full description of staff requirements and how to do things to them by the supervisor.

- Elimination of discrimination between contractual staff and official personnel in cases such as welfare, recreational and financial facilities

- Establishing friendly relations with colleagues

- The suitability of the job and the position of employees with their education and morale

- Establishing meritocracy, lack of high personnel turnover, creating a sense of responsibility, creating job stability, etc. are also considered important factors in increasing organizational commitment.

- The outcomes of the study may lead to draw whether there is a statistically significant relationship between the organizational commitment and the financial performance of the selected banking institution and recommendations can be made that how financial performance can be improved by strengthening the dimensions of competence as indicators of organization

\subsection{Practical suggestions}

In many countries, corporate laws and regulations have been ratified and implemented, which has an important role in fiscal coherence and more information about the development of the organization. According to the literature of this research, suggestions can be made for the next steps of organizations in order to provide better performance and increase organizational commitment of employees.

1. Organizing regular sessions and presenting the results of meetings in the framework of the circular and informing staff about the goals and missions of the organization and its desirable cultural values by introducing and celebrating sample individuals and behavioral patterns.

2. Creation of financial and recreational facilities for employees in the absence of the possibility of increasing their salaries and benefits by providing recreational facilities such as travel plans, sports clubs, swimming pools, shopping malls, play centers, restaurants, etc. for staff and their families, especially for contractual staff with fewer opportunities and usually more than formal staff. Increasing incomes and creating going and returning facilities can also be useful in this regard.

3. Encouraging employees to get married by creating facilities such as mortgages, marriage loans, etc.

4. Increasing employees' satisfaction by using their biorhythms information and timely staff turnover, and avoiding unnecessary turnovers using the maximum staffing power.

5. Create and strengthen teams of work and increase group rewards and award special rewards to the superior unit instead of the superior person.

6. Creating a center for counseling and social working for staff, and examining the administrative and even family problems of them to reduce stress and stress caused by work problems and provide better performance.

7. More attention to human skill and public relations of middle managers and directors when choosing them to make them more effective in establishing communication and clarifying it between staff and top managers and holding training courses for middle managers .

8. Managers are advised to create a supportive environment in the organization where possible and provide required incentives to increase employee quest because, according to the opinion of the experts, organizational commitment can only affect the employee's efforts and through that, the person's efforts in his performance increase.

9. Identify the training needs of the staff and, by addressing these needs, enhance their skills and abilities.

\subsection{Suggestions for future research}

In this regard, for further research in this area, the following suggestions are required:

1. The study of the effects of factors such as job security, honesty, justice, meritocracy and the role of management and leadership on increasing organizational commitment of employees

2. An Investigation of the effect of employee contract type on employees' organizational commitment

3. Measurement of the appropriateness of control systems as one of the important factors in increasing organizational commitment and considering the empowerment of employees, delegation of authority and selfcontrol systems in this regard.

4. Study and examine the effects of flexible work plan on job satisfaction and consequent increase of organizational commitment.

5. Investigating the results and consequences of organizational commitment in different organizations. 


\section{References}

Abbaszadeh, S. M. (2004). Management Principles and Concepts (Edition 2). Tehran : Soroush. Abualaie, B. (2006). The thinker human resources is an asset of an organization. Journal of Management Age, I, 6872.

Baqeri, M., \& Tavanaie, R. (2010). Effect of Organizational Commitment on Organizations' Performance. Scientific Two-Monthly Journal of Police Human Development, 13, 232-243.

Benkhoff, B. (1997). Ring commitment is costly: new approaches establish the missing link between commitment and performance. Human Relation. 50(6), 701- 726.

Chompookum, D., \& Derr, B. C. (2004). The Effects of Internal Orientations on Organizational Citizenship Behavior. Thailand Career Development International, 9, 406-423.

Cohen, A. (2007). Commitment before and after: an evaluation and reconceptualization of organizational commitment. Human resource management review, 3,356-375.

Haghighat, Monfared Jalal, Hazrati, AliAvaset, \& Mirzazadeh, Hojat (2010). The Relationship between Business commitment. Management Quarterly, 2(6), 22-32.

Hajloo, Nader, Naser, Sobhi G., \& Hossein, Bahrami Razaghi (2013). Psychological Advances of Organizational Commitment. Journal of Psychological Studies, 2(2), 58-74.

Hosseini, S. M., \& Ali, Mehdizadeh Ashrafi (2009). Identification of factors affecting organizational commitment. Management Quarterly, 7(18), 132-144.

Hoveyda, Reza, Mokhtari, Hojatollah, \& Forouhar, Mohammad (2012). The Relationship between Components of the Psychological Capital and Components of Organizational Commitment. Journal of Research in Cognitive and Behavioral Sciences, 2 (II), 43-56.

Jafarzadeh, Maryam (2005). A study on the level of organizational commitment of employees of National Refinery and Distributing Iranian Oil Products and its relationship with some of their demographic characteristics. Educational Management Dissertation. Islamic Azad University, Science and Research Branch.

Jaramillo, f., Nixon, R., \& Sms, P. (2005). The Effect of Law Enforcement Stress on Organizational Commitment. International Journal of Police Strategy and Management, 28, 321-336.

Mahdad, Ali (2010). Industrial/Organizational Psychology( Edition 7). Tehran: Jungle Publishing.

Masterson, S. S. (2001). A Trickle-Down Model of Organizational Justice: Relating Employees' and Customers' Perceptions and Reactions to Fairness. Journal of Applied Psychology, 86 (4), 594-604.

Norouzi, Seyed, Hosseini, Rasool, \& Masoumeh, Kalateh Seyfari (2014). Effect of Organizational Entrepreneurship on Organizational Socialization and Organizational Commitment of Staff of Physical Education Institutions of Mazandaran Province. Sports Management, 6(1), 89-108.

Poursoltani, Hossein, Andam, Reza, \& Faraji, Rasoul (2012). Relationship between Organizational Excellence and Organizational Commitment in the General Physical Education Departments of Iran's Selected Provinces. TwoMonth Journal of Sports Management and Motion Behavior, 2( 3), 222-232.

Ramezanian, M. R., Abdollahian, F., \& Kalate Seyfi, M. (2013). Investigating dimensions of managers' tendency to decisions making and their impact on organizational commitment: Service Organizations of Gilan Province. Management Improvement Quarterly, 7(1), 86-109.

Robbins, S. P. (2005). Organizational behavior(11 the Ed). New York: prenticehall.

Salajegh, Sanjar, \& Honaramooz, Sahar (2010). Suggestion System, A Way to Establishing Participatory Management. Yas Strategy, 24, 254-276.

Shafaghat, Abutaleb, Zahedi, M. J., \& Nazoktabar, Hossein (2013). Impact of Organizational Commitment on Performance of Industrial Companies based on Miller et al.'s Model. Management Improvement Quarterly. 7(1), $70-85$.

Shirkavand, Shahram (2004). Organizational Spirituality and Atmosphere. Payam Journal of Iran Khodro. 8(95), 59-60.

Shiuan, C. B., and Yu, J. D. (2003). Organizational commitment, supervisory commitment and employee outcomes in the Chinese context proximal hypothesis or global hypothesis. Journal of Organizational Behavior, 2(24), 32-38. Siders, M. A., Gerard, G., and Ravi, D. (2001). The Relationship of Internal and External Commitment Foci to Objective Job performance Measures. Academy of management Journal, 44 (3), 570-579.

Stewart, Gregory (2008). lee, the Relationship of Emotional intelligence to job satisfaction and organizational commitment, Regent University, 2008. 